ORIGINAL ARTICLE / ARTIGO ORIGINAL

\title{
Analysis of early and late maternal complications associated with delivery using propensity score
}

\author{
Análise das complicações maternas precoces e tardias associadas à via de \\ parto utilizando escore de propensão
}

\author{
Keila Cristina Mascarello' (D), Alicia Matijasevich2,3 (D), Aluisio Jardim Dornellas de Barros² (D), \\ Fernando Celso Lopes Fernandes de Barros ${ }^{4}$ (D), Iná da Silva dos Santos ${ }^{2,5}$ (D), \\ Jeremy Alexander Labrecque ${ }^{6}$ (D), Mariângela Freitas Silveira² (D)
}

\begin{abstract}
Objective: To analyze early and late maternal complications associated with the mode of delivery in a birth cohort in Brazil, using the propensity score technique for analysis. Methods: This is a prospective cohort study, using data from the Pelotas Birth Cohort, RS, 2004. A total of 4,189 women were included and a descriptive analysis of the data and subsequent calculation of the propensity and pairing score of vaginal delivery women and cesarean delivery women with similar scores (1,366 pairs). We then assessed the difference in outcome risk between the groups. Results: Women in the cesarean group had 2.9 percentage points (pp) more risk of postpartum infection, 1.13 p.p. more risk of urinary infection, 1.10 p.p. more risk of anesthetic complications and 1.24 p.p. higher risk of headache compared to vaginal delivery, but less risk of anemia $(-2.43$ pp) and hemorrhoids (-1.24 p.p.). The use of propensity scores is extremely useful for reducing bias and increasing accuracy in observational studies when experimental studies cannot be performed. Conclusion: Cesarean sections have been associated with a higher prevalence of postpartum and urinary tract infections, anesthetic complications and headache and lower prevalence of anemia and hemorrhoids, so they should be performed with clear indications and when their benefits outweigh potential risks.
\end{abstract}

Keywords: Cesarean section. Natural childbirth. Puerperal disorders. Epidemiology.

\footnotetext{
'Department of Health Sciences, Universidade Federal do Espírito Santo - São Mateus (ES), Brazil.

²Epidemiological Research Center, Post-Graduation Program in Epidemiology, Universidade Federal de Pelotas - Pelotas (RS), Brazil. ${ }^{3}$ Department of Preventive Medicine, School of Medicine, Universidade de São Paulo - São Paulo (SP), Brazil.

${ }_{4}^{4}$ Post-Graduation Program in Health and Behavior, Universidade Católica de Pelotas - Pelotas (RS), Brazil.

${ }^{5}$ Post-Graduation Program in Pediatrics and Child Heallth, School of Medicine, Pontifícia Universidade Católica do Rio Grande do Sul - Porto Alegre (RS), Brazil.

${ }^{6}$ Department of Epidemiology, Erasmus MC - Rotterdam, the Netherlands.

Corresponding author: Keila Cristina Mascarello. Rodovia Governador Mário Covas, Km 60, DCS, sala 13, Litorâneo, CEP: 29932540, São Mateus, ES, Brasil. E-mail: keilamascarello@gmail.com

Conflict of interests: none to declare - Financial support: The study "Coorte de Nascimentos de Pelotas, 2004", conducted by the Postgraduation Program in Epidemiology, Federal University of Pelotas, with support fromn the Associação Brasileira de Saúde Coletiva (ABRASCO). From 2009 to 2013, the 2004 birth cohort was funded by the Wellcome Trust. Previous phases of the study were supported by the World Health Organization, Support Program for Centers of Excellence (PRONEX), National Council for Scientific and Technological Development (CNPq), Ministry of Health and Pastoral da Criança. AM, AJDB, ISS, FCB and MFS received a Research Productivity Grant from CNPq.
} 
RESUMO: Objetivo: Analisar as complicações maternas precoces e tardias, associadas à via de parto, em uma coorte de nascimentos no Brasil, utilizando para a análise a técnica de escores de propensão. Métodos: Trata-se de estudo do tipo coorte prospectiva, utilizando dados da Coorte de Nascimentos de Pelotas (RS), de 2004. Incluíram-se 4.189 mulheres, e realizaram-se análise descritiva dos dados e posterior cálculo do escore de propensão e pareamento das mulheres de parto vaginal com as mulheres de parto cesárea com escores semelhantes (1.366 pares), avaliando a diferença no risco do desfecho entre os grupos. Resultados: As mulheres do grupo cesárea apresentaram 2,9 pontos percentuais (p.p.) a mais de risco de infecção pós-parto, 1,13 p.p. a mais de risco de infecção urinária, 1,10 p.p. a mais de risco de complicações anestésicas e 1,24 p.p. a mais de risco de cefaleia que as de parto vaginal, porém apresentaram menor risco de anemia (-2,43 p.p.) e hemorroidas (-1,24 p.p.). A utilização de escores de propensão é extremamente útil para a redução de vieses e o aumento da precisão em estudos observacionais, quando estudos experimentais não podem ser realizados. Conclusão: As cesáreas associaram-se a maiores prevalências de infecções pós-parto e urinária, complicações anestésicas e cefaleia e menores prevalências de anemia e hemorroidas, portanto devem ser realizadas com indicações claras e quando seus benefícios superam potenciais riscos.

Palavras-chave: Cesárea. Parto normal. Transtornos puerperais. Epidemiologia.

\section{INTRODUCTION}

The constant and unprecedented increase in cesarean rates has raised the interest of investigators on this mode of delivery, as well as the concern of government agencies, managers and health care provides in the maternal and child area, especially due to the potential for maternal and child complications related to elective surgical delivery procedure without indication.

Worldwide, cesarean rates went from $6.7 \%$ in 1990 to $19.1 \%$ in 2014, which represents an increase of $12.4 \%$ in the period and $4.4 \%$ per year, with great inequities among countries ${ }^{1}$. In less developed countries, with poorer health systems and difficulties in accessing the necessary cesarean sections, who would therefore benefit more from this increase, the rate rose by only 4.2 percentage points (1.9 to $6.1 \%$ ) in the same period. This shows that increased rates occurred in regions already having greater access to health services and obstetric care and already showing high cesarean rates ${ }^{1}$, and that would not result in maternal and child benefits but in potential additional risks.

Brazil has one of the highest cesarean rates in the world, with $56 \%$ of births in 2018 performed by surgery ${ }^{2}$. Of these, it is estimated that the majority occurred without precise medical indication and without considering their potential risks, since $84 \%$ of cesarean sections in Brazil were performed outside the labor period ${ }^{3}$, even when the current evidence points to few and infrequent situations for the indication of a cesarean section scheduled before labor ${ }^{4}$. The performance of the procedure is strongly associated with higher maternal education and the most favored social classes, possibly performed for convenience and without a clear clinical indication ${ }^{5}$. 
The high percentages of cesarean sections without medical indication are associated with an increased risk of maternal complications, not only obstetric complications but also those resulting from any surgical procedure ${ }^{6}$. However, among the studies that evaluated complications associated with the mode of delivery, few used primary data from prospective research, and even in those, there was difficulty in separating the risks to which pregnant women were previously exposed from those inherent to the surgical procedure. New types of analysis are needed to minimize or eliminate bias, since for the subject in question, it is ethically unacceptable to conduct a randomized clinical trial, subject pregnant women to unnecessary cesarean sections.

Thus, this study aimed to analyze the early and late maternal complications associated with mode of delivery, in a cohort of births in Brazil, using the propensity score technique for analysis.

\section{METHODS}

This was a prospective cohort study, using data from the 2004 Pelotas (RS) Births Cohort. This cohort included all births that occurred in 2004 to mothers living in the urban area of Pelotas and in the Jardim América neighborhood, belonging to the municipality of Capão do Leão, next to Pelotas ${ }^{7}$.

In 2004, 4,263 children were born in Pelotas, and their mothers were invited to participate in the study, in which the puerperal woman was interviewed and the newborn evaluated (perinatal study). The mothers of 4,231 children agreed to participate in the study. Follow-up visits for these children took place at home at 3,12, 24 and 48 months and at the clinic of the Epidemiological Research Center at Universidade Federal de Pelotas at 6 and 11 years of age. At each visit, interviews were conducted by trained interviewers, using standardized questionnaires. A total of 3,985 children and their mothers were followed up at 3 months, 3,907 at 12 months, 3,869 at 24 months, 3,799 at 48 months, 3,722 at 6 years and 3,566 at 11 years $^{7}$. From the beginning of the study until 11 years follow-up, there were 98 deaths along with losses and refusals, totaling 567 children (13.4\%). The current study used data collected in the perinatal study (2004) and in follow-ups, up to and including 6 years of age. More methodological details, with sample characteristics, can be obtained in another publication $^{7}$. In the present study, 4,189 women were included, given the exclusion of those who had multiple pregnancies.

Information on demographic, socioeconomic and obstetric characteristics obtained from the perinatal study was used. Data on complications were obtained in other follow-ups, when women were asked about the reasons for staying in the hospital or readmission after childbirth and the occurrence or not of the complications studied (for the cystocele outcomes, genital prolapse and perineum rupture, the question was about medical diagnosis). Information on early complications was obtained up to 48 months follow-up and, on late complications, at 6 years follow-up. To assess early complications, women were included 
who provided information on complications related to childbirth in at least one of the follow-ups after the perinatal period ( $\mathrm{n}=3,984 ; 95.1 \%)$; and, for late complications, all women participating in the 6 years follow-up with information about these complications $(\mathrm{n}=3,430$; $80.8 \%$ ), with $92.1 \%$ of the participants being followed up at 6 years of age.

Complications related to childbirth, obtained in follow-up, according to the woman's report, were considered as outcomes, which were later classified according to the International Classification of Diseases and Health-Related Problems, 10th edition (ICD-10). Early complications were evaluated together (presence of one or more complications) and separately, including postpartum infection, anemia, hemorrhage, urinary tract infection, pain, headache, anesthetic complications, hemorrhoids, curettage and adhesions at the surgery site/episiotomy. Late complications were also assessed together and separately and consisted of urinary and fecal incontinence, dyspareunia, cystocele, genital prolapse and perineum rupture.

The variables used to characterize the mothers were age at the time of delivery, education in full years, asset index $(\mathrm{AI})^{8}$, living with a husband or partner, skin color observed by the interviewer, type of childbirth care provider (Unified Health System - SUS - yes or no), parity and number of prenatal visits.

The propensity score was estimated by logistic regression and offered the probability of cesarean delivery conditioned to the characteristics of the woman. After calculating the propensity score, cesarean delivery women were paired with vaginal delivery women with similar scores using the nearest neighbor technique. After estimating the propensity score, 2,732 women could be included, paired 1:1, totaling 1,366 pairs, similar. The other women were excluded for lack of similar peers or missing information. Pairing was carried out using the variables age, parity, skin color, education, AI, cared by SUS, number of prenatal visits, anemia during prenatal care and bleeding in the last three months of pregnancy.

The estimate of association between exposure and the outcomes studied was therefore the difference in risk in percentage points (p.p.) of the outcome between the cesarean and vaginal delivery groups, which was interpreted as the effect of cesarean sections on the outcome in women of cesarean section. This estimate is known as the average treatment effect among the treated, being the most appropriate for this study, since the objective was to determine the effects of cesarean section on women undergoing this mode of delivery, and not the effect if all women were subjected to the procedure (average treatment effect). The analyses were performed with the Stata 14.0 statistical program using the command teffects psmatch ${ }^{9}$ (teffects psmatch (outcome) (exposure to confounding variables), atet $\mathrm{nn}(1)$ ), which allows modeling, through logistic regression, the outcome probability (postpartum complications) depending on the mode of delivery, with vaginal delivery as a reference.

The study protocol was approved by the Ethics and Research Committee of the Faculty of Medicine of the Federal University of Pelotas (UFPel) and meets the standards of Resolution No. 196/96 of the National Health Council, in force at the time of the research. In each follow-up, participants were asked to sign an informed consent form, after resolving doubts regarding the research procedures. 


\section{RESULTS}

Table 1 presents the sociodemographic and reproductive characteristics of the 4,189 puerperal women from whom similar pairs could be extracted. About a fifth of mothers (19\%) were under 20 years of age, $27.2 \%$ were between 20 and 24 and $13.3 \% 35$ or older. As for education, $43.1 \%$ had nine or more years of study at the time of the interview, $20 \%$ were black and $81 \%$ had delivery by SUS. Just over half $(54.9 \%)$ of the mothers had a vaginal delivery, $66.1 \%$ of whom had an episiotomy (information not shown in the tables).

Table 1. Sociodemographic, reproductive and obstetric characteristics of the mothers of children belonging to the Pelotas Birth Cohort, according to mode of delivery.

\begin{tabular}{|c|c|c|c|}
\hline & $\mathrm{n}(\%)$ & $\begin{array}{c}\text { Vaginal delivery } \\
\mathrm{n}=2.300(54.91 \%)\end{array}$ & $\begin{array}{c}\text { Cesarean } \\
n=1.889(45.09 \%)\end{array}$ \\
\hline Age $(n=4,187)$ (years) & $\mathrm{p}<0.001^{*}$ & & \\
\hline$<20$ & $796(19.0)$ & 524 (22.79) & $272(14.41)$ \\
\hline $20-24$ & $1,137(27.2)$ & $692(30.10)$ & $445(23.57)$ \\
\hline $25-29$ & $948(22.6)$ & $493(21.44)$ & $455(24.10)$ \\
\hline $30-34$ & $748(17.9)$ & $325(14.14)$ & $423(22.40)$ \\
\hline 35 or more & $558(13.3)$ & $265(11.53)$ & $293(15.52)$ \\
\hline Education $(n=4,147)$ (years) & $\mathrm{p}<0.001^{*}$ & & \\
\hline $0-4$ & $647(15.6)$ & $450(19.65)$ & $197(10.61)$ \\
\hline $5-8$ & $1,711(41.3)$ & $1,069(46.68)$ & $642(34.57)$ \\
\hline 9 or more & $1,789(43.1)$ & $771(33.67)$ & $1,018(54.82)$ \\
\hline Asset index $(n=3,234)$ & $\mathrm{p}<0.001^{*}$ & & \\
\hline 1st quintile (poorest) & $700(21.6)$ & $479(27.23)$ & $221(14.98)$ \\
\hline 2nd quintile & $614(19.0)$ & $393(22.34)$ & $221(14.98)$ \\
\hline 3rd quintile & $629(19.4)$ & $355(20.18)$ & $274(18.58)$ \\
\hline 4th quintile & $644(19.9)$ & 348 (19.78) & $296(20.07)$ \\
\hline 5th quintile (wealthiest) & $647(20.0)$ & $184(10.46)$ & $463(31.39)$ \\
\hline Lives with partner $(n=4,189)$ & $\mathrm{p}<0.001^{*}$ & & \\
\hline No & $687(16.4)$ & $423(18.39)$ & $264(13.98)$ \\
\hline Yes & $3,502(83.6)$ & $1,877(81.61)$ & $1,625(86.02)$ \\
\hline
\end{tabular}


Table 1. Continuation.

\begin{tabular}{|c|c|c|c|}
\hline & $\mathrm{n}(\%)$ & $\begin{array}{c}\text { Vaginal delivery } \\
\mathrm{n}=2.300(54.91 \%)\end{array}$ & $\begin{array}{c}\text { Cesarean } \\
n=1.889(45.09 \%)\end{array}$ \\
\hline Skin color $(n=4,189)$ & $p=0.024^{*}$ & & \\
\hline White & $3,060(73.0)$ & $1,644(71.48)$ & $1,416(74.96)$ \\
\hline Black & $837(20.0)$ & $494(21.48)$ & $343(18.16)$ \\
\hline Other & $292(7.0)$ & $162(7.04)$ & $130(6.88)$ \\
\hline Type of provider $(n=4,184)$ & $p<0.001^{*}$ & & \\
\hline SUS & $3,393(81.1)$ & $2,171(94.60)$ & $1,222(64.69)$ \\
\hline Not SUS & 791 (18.9) & $124(5.40)$ & $667(35.31)$ \\
\hline Number of prenatal visits $(n=4,011)$ & $p<0.001^{*}$ & & \\
\hline $0-3$ & $291(7.3)$ & $225(10.21)$ & $66(3.65)$ \\
\hline 4-6 & $871(21.7)$ & $584(26.50)$ & $287(15.88)$ \\
\hline $7-9$ & $1,499(37.4)$ & $838(38.02)$ & $661(36.58)$ \\
\hline 10 or more & $1,350(33.7)$ & $557(25.27)$ & $793(43.88)$ \\
\hline Parity $(n=4,188)$ & $p<0.001^{*}$ & & \\
\hline 1 & $1,655(39.5)$ & 837 (36.39) & $818(43.33)$ \\
\hline 2 & $1,098(26.2)$ & 584 (25.39) & $514(27.22)$ \\
\hline 3 & $669(16.0)$ & 377 (16.39) & $292(15.47)$ \\
\hline 4 & $349(8.3)$ & $225(9.78)$ & $124(6.57)$ \\
\hline 5 or more & $417(10.0)$ & $277(12.05)$ & $140(7.41)$ \\
\hline
\end{tabular}

SUS: Unified Health System; *Pearson $\chi^{2}$ test.

Most women who underwent cesarean delivery had nine or more years of study (54.8\%), were between 20 and 29 years old (47.7\%), lived with a partner $(86 \%)$, were white $(74.9 \%)$, had the delivery covered by SUS (64.7\%), and had 10 or more prenatal visits (43.9\%). Other characteristics are shown in Table 1.

Figure 1 shows the distribution of the propensity score and the distribution of paired women. Above the 0 axis, women with cesarean delivery are located and below the women with vaginal delivery. The gray bars represent the women who had compatible pairs $(2,732)$, and the white bars, those excluded from the analysis. There was a good distribution of the propensity score in both groups and, among those with a high probability of cesarean section, the other characteristics were similar between those of the cesarean group and the vaginal group. 


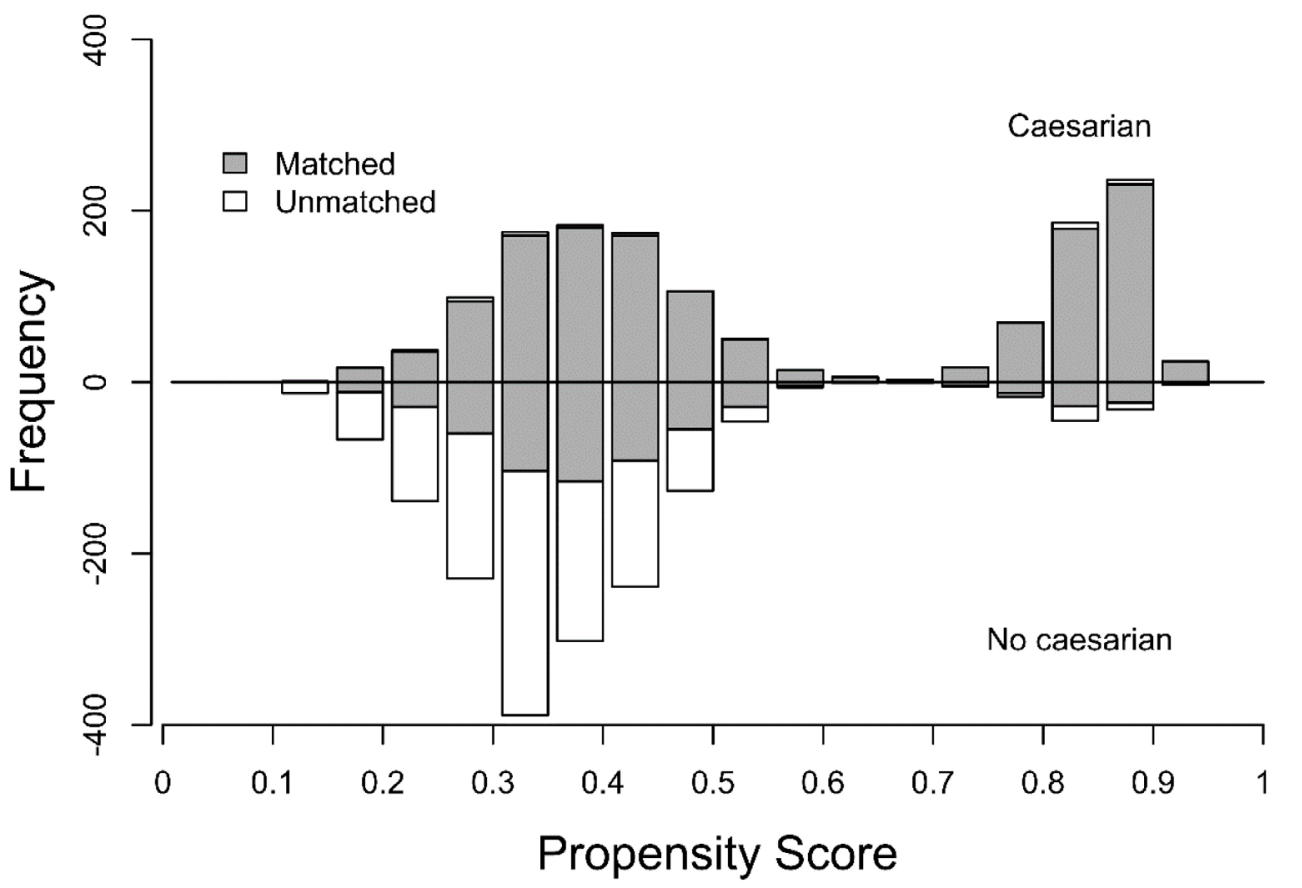

Figure 1. Distribution of the propensity score among the mothers of children belonging to the 2004 Pelotas Birth Cohort.

The incidence of early obstetric complications in paired women was $12.1 \%$, being $10.9 \%$ in mothers with vaginal delivery and $13.4 \%$ in those with cesarean delivery $(p=0.046)$ (Table 2). Postpartum infections were the most frequent early complications in both groups (3.1\% in the vaginal delivery group and $5.0 \%$ in the cesarean section). Six years after the birth of the 2004 child, late complications were more prevalent in the normal delivery group $(23.8 \%)$ than in the cesarean section $(18.1 \%)$ (Table 2$)$. Urinary incontinence was the most frequent late complication, affecting $14.3 \%$ of women in the vaginal delivery group and $9.7 \%$ in the cesarean section.

Table 2 presents the logistic regression analyses using the propensity scores, with the reference group being women of vaginal delivery (untreated). There was no difference between women who had a cesarean section and those who had a vaginal delivery when early complications were considered together. When early complications were analyzed separately, women in the cesarean group had 2.9 p.p. more risk of postpartum infection $(95 \% \mathrm{CI} 0.80-$ $5.02), 1.13$ p.p. more risk of urinary tract infection (95\% CI $0.33-1.94), 1.10 \mathrm{pp}$ (95\%CI 0.50 $-1.70)$ at higher risk of anesthetic complications (95\%CI $0.50-1.70)$ and 1.24 p.p. more risk of headache $(95 \% \mathrm{CI} 0.62-1.87)$, but had a lower risk of anemia $(-2.43$ p.p., $95 \% \mathrm{CI}-4.86-0)$ and hemorrhoids (-1.24 pp, 95\%CI -1.98--0.49). 
Table 2. Difference in risk of early and late maternal complications associated with the mode of delivery among the mothers of children belonging to the 2004 Pelotas Birth Cohort, calculated using the propensity score $(n=2,732)$.

\begin{tabular}{|l|c|c|c|c|c|c}
\hline & $\begin{array}{c}\text { Vaginal delivery } \\
(\mathrm{n}=1,366) \\
\mathrm{n}(\%)\end{array}$ & $\begin{array}{c}\text { Cesarean } \\
(\mathrm{n}=1,366) \\
\mathrm{n}(\%)\end{array}$ & $\begin{array}{c}\text { Difference } \\
\text { in risk } \\
(\%)^{*}\end{array}$ & $\begin{array}{c}\text { Standard } \\
\text { error }\end{array}$ & $95 \% \mathrm{Cl}$ & p-value \\
\hline $\begin{array}{l}\text { Early } \\
\text { complications }\end{array}$ & $149(10.1)$ & $183(13.4)$ & 2.84 & 0.02031 & $-1.14-6.82$ & 0.162 \\
\hline Hemorrhage & $23(1.7)$ & $24(1.8)$ & -0.38 & 0.00842 & $-2.03-1.27$ & 0.650 \\
\hline $\begin{array}{l}\text { Postpartum } \\
\text { infection }\end{array}$ & $43(3.1)$ & $69(5.0)$ & 2.91 & 0.01076 & $0.80-5.02$ & 0.007 \\
\hline Anemia & $37(2.7)$ & $18(1.3)$ & -2.43 & 0.01241 & $-4.86-0.00$ & 0.050 \\
\hline $\begin{array}{l}\text { Urinary } \\
\text { infection }\end{array}$ & $6(0.4)$ & $23(1.7)$ & 1.13 & 0.00410 & $0.33-1.94$ & 0.006 \\
\hline Pain & $11(0.8)$ & $26(1.97)$ & 1.31 & 0.00675 & $-0.02-2.63$ & 0.053 \\
\hline $\begin{array}{l}\text { Anesthetic } \\
\text { complications }\end{array}$ & $2(0.1)$ & $16(1.8)$ & 1.10 & 0.00306 & $0.50-1.70$ & $<0.001$ \\
\hline Headache & $4(0.3)$ & $18(1.3)$ & 1.24 & 0.00317 & $0.62-1.87$ & $<0.001$ \\
\hline Hemorrhoids & $22(1.6)$ & $2(0.1)$ & -1.24 & 0.00380 & $-1.98--0.49$ & $<0.001$ \\
\hline Curettage & $7(0.5)$ & 0 & -0.66 & 0.00441 & $-1.52-0.21$ & 0.135 \\
\hline Hysterectomy & $6(0.4)$ & $2(0.1)$ & -0.73 & 0.00455 & $-1.62-0.16$ & 0.107 \\
\hline $\begin{array}{l}\text { Late } \\
\text { complications }\end{array}$ & $325(23.8)$ & $247(18.1)$ & -5.44 & 0.02521 & $-10.38--0.50$ & 0.031 \\
\hline $\begin{array}{l}\text { Urinary } \\
\text { incontinence }\end{array}$ & $196(14.3)$ & $133(9.7)$ & -4.68 & 0.02070 & $-8.73--0.62$ & 0.024 \\
\hline $\begin{array}{l}\text { Fecal } \\
\text { incontinence }\end{array}$ & $57(4.8)$ & $41(3.0)$ & -1.22 & 0.01632 & $-4.42-1.98$ & 0.455 \\
\hline Dyspareunia & $82(6.0)$ & $124(9.1)$ & 2.08 & 0.01513 & $-0.89-5.04$ & 0.17 \\
\hline Cystocele & $65(4.8)$ & $27(2.0)$ & -1.06 & 0.01142 & $-3.30-1.18$ & 0.352 \\
\hline $\begin{array}{l}\text { Genital } \\
\text { prolapse }\end{array}$ & $9(0.7)$ & $12(0.9)$ & -0.25 & 0.00655 & $-1.53-1.04$ & 0.705 \\
\hline $\begin{array}{l}\text { Perineum } \\
\text { rupture }\end{array}$ & $7(0.5)$ & $7(0.5)$ & -0.75 & 0.00657 & $-2.03-0.54$ & 0.257 \\
\hline Cesan & & & & & \\
\hline
\end{tabular}

${ }^{*}$ Cesarean compared to vaginal delivery, in percentage points (p.p.).

Taken together, late complications were 5.44 p.p. less frequent in the group who underwent cesarean section $(95 \%$ CI $-10.38--0.50)$. Separately, from late complications, only the prevalence of urinary incontinence differed according to the mode of delivery, with 4.68 p.p. lower in the group with cesarean section (95\%CI -8.73--0.62). 


\section{DISCUSSION}

This is the first study to assess the risk of maternal complications associated with cesarean section using the propensity score for analysis and, therefore, the one that most closely matches the results that could be found in a randomized clinical trial. The fact that this is a prospective cohort study, with primary data, with few losses and a long follow-up period, also increases the quality of the evidence.

Among early complications, cesarean delivery was associated with a higher risk of postpartum infection, urinary tract infection, anesthetic complications and headache and a lower risk of anemia and hemorrhoids. Among late complications, cesarean delivery was associated with a lower risk of urinary incontinence, with the greatest difference between the two groups (about 5 p.p. less in the group that underwent cesarean section). After urinary incontinence, the greatest differences between the two groups were observed in terms of the risk of postpartum infection (about 3 p.p. greater in the cesarean group) and the risk of anemia, 2.4 p.p. lower in those with cesarean section.

Due to the low incidence of serious complications in the population studied, such as death, hospitalization in an intensive care unit or other near miss events, it was not possible to evaluate these outcomes.

Other studies have also found a higher risk of postpartum infection in women with cesarean sections, as expected in any surgical procedure ${ }^{10,11}$. The increased risk of infection should be an important point to be considered in determining the mode of delivery, as it is a potentially serious complication, with the possibility of evolution to death ${ }^{10,11}$, especially when not diagnosed and treated in a timely manner.

Anesthetic complications were also more frequent in women undergoing cesarean delivery, obviously because it is a surgical procedure and because it is not routine in Brazil to use anesthesia during labor and vaginal delivery. Regardless, this is a risk that should be considered when performing a cesarean section, especially when not medically indicated. Headache was also more frequent among women delivered by cesarean section, which may be associated with anesthetic techniques. Another Brazilian study found a higher risk of death from anesthetic complications among cesarean women ${ }^{12}$.

Women who had a cesarean delivery had a lower risk of urinary incontinence during the study period, compared to women who delivered vaginally. A systematic review that evaluated pelvic floor dysfunction also found a higher risk of urinary incontinence in women in vaginal delivery, but this difference tended to decrease over time, equaling the prevalence of urinary incontinence around 50 years of age among women who had vaginal or cesarean delivery ${ }^{13}$. In high-income countries, the prevalence of urinary incontinence varies between 25 and $45 \%$, while the prevalence of stool and gas incontinence is 11 to $15 \%{ }^{13}$.

Cesarean sections, especially when their risks outweigh the potential benefits, can cause significant and even permanent complications, such as sequelae and deaths, especially in places with little infrastructure, without the capacity to perform surgeries safely and treat peri- and postoperative complications, making this technology usable only when truly 
necessary ${ }^{14}$. In a Brazilian population-based study, cesarean section was associated with a significantly increased risk of maternal mortality (adjusted OR $=2.9$; 95\%CI 1.6 - 5.1), mainly due to hemorrhage and anesthetic complications ${ }^{12}$.

Our study found no relationship between postpartum hemorrhage or hysterectomy and the mode of delivery, controversial associations in the literature. A study by Liu et al. ${ }^{15}$ demonstrated this controversy by finding among cesarean delivery women a higher risk of hysterectomy $(\mathrm{OR}=2.1 ; 95 \% \mathrm{CI} 1.2-3.8)$ and a lower risk of blood transfusion $(\mathrm{OR}=0.4$; $95 \%$ CI $0.2-0.8$ ), both of which are consequences of postpartum hemorrhage. Another study found three times the risk of hemorrhage among cesarean women ${ }^{16}$. Although it is difficult to establish a relationship between hemorrhage and delivery, it is consistent in the literature that women with cesarean delivery are more likely to need blood transfusion ${ }^{17-19}$ and hysterectomy ${ }^{15,17,18.20}$, when compared to women with vaginal delivery, which points to more serious hemorrhage among women in surgical delivery.

The prevalence of cesarean sections in this study was 45.1\%. Since 2009, in Brazil, cesarean delivery rates have surpassed those for vaginal delivery, having peaked in 2014, when $57 \%$ of births involved surgery. In the years 2015, 2016, 2017 and 2018, there were slight variations in this percentage, with rates of 55.5, 55.4, 55.6 and $56.0 \%$, respectively ${ }^{2}$.

For many years, the World Health Organization (WHO) has recommended that cesarean deliveries should not exceed $15 \%$ of total births, but they have become more and more frequent worldwide. In view of the manifestations of researchers and the international community, in 2014, the WHO began to recommend that efforts be concentrated on ensuring that cesarean sections are performed in cases where they are necessary, instead of seeking to achieve a specific rate of cesarean sections ${ }^{14}$. The document, based on a systematic review, also states that a cesarean section is an effective intervention to save the lives of mothers and babies, but only when indicated for medical reasons, and that, at the population level, cesarean rates greater than $10 \%$ are not associated with a reduction in maternal and neonatal mortality ${ }^{14}$. However, a more recent study indicates that cesarean sections of up to $20 \%$ may be protective of maternal and neonatal mortality and that previous estimates regarding the percentage were possibly underestimated ${ }^{21}$.

The perception on the part of pregnant women and professionals that cesarean section is a risk-free procedure is often due to the relative rarity of serious maternal events during childbirth and postpartum, contributing to a mistaken perception of safety ${ }^{22}$.

Despite the importance of this study, there are limitations that must be considered. Information regarding childbirth and women's characteristics was collected in 2004 and may therefore differ from the current profile of women who undergo vaginal or cesarean delivery, although the analysis technique is able to minimize the effect of covariates on the outcome.

The use of propensity scores is extremely useful for reducing bias and increasing precision in observational studies and aims to correct the estimate of the treatment effect; this creates a situation similar to that of experimental studies, reducing bias even when randomization was not or could not be done ${ }^{23}$, when controlling the variables measured 
and used in the pairing. For example, predictive characteristics of patients who preferentially receive a particular treatment can lead to a greater risk of developing the study outcome, so the assessment of the effect of a treatment will depend on the approach of baseline differences between treated and untreated groups. The use of this method allows the balancing of baseline characteristics (covariates) between the treated and untreated groups, providing an unbiased estimate of effect. Thus, it is possible to evaluate the determinants of treatment, in addition to their effects, in more detail than through conventional regression models ${ }^{24}$.

It was also not possible to assess the real indications for surgical delivery, but the high percentage of cesarean sections suggests that most of them had no real medical indication. A previous study carried out with the same population made an attempt to identify which cesarean sections were elective, but this information was impossible to obtain in the records or in the interviews with the doctors, as they were reluctant to admit that the procedure had no medical indication ${ }^{25}$. In addition, the six-year follow-up period may have been short for the onset and detection of late complications, which could arise later in the woman's life. In addition, the analysis did not consider the mode of delivery of possible pregnancies before or after 2004, which could influence the presence of complications, and whether the cesarean sections occurred before or after the start of labor, which can affect the occurrence of maternal complications.

The fact that complications are self-reported is also a limitation of this study, since the diagnosis may depend on other characteristics of women, such as self-perceived health and access to health services. Therefore, the prevalence of complications may have been underestimated both in the cesarean section and in the vaginal delivery group.

Despite the limitations, the quality of the information, the low percentage of losses and the analysis techniques used provide the results with greater reliability. New studies with large populations should also be encouraged, allowing the identification of possible risks for more rare events associated with cesarean sections, such as death and near miss events, using analyses with propensity scores and thus reducing the possibility of bias.

\section{REFERENCES}

1. Betrán AP, Ye J, Moller AB, Zhang J, Gülmezoglu AM, Torloni MR. The Increasing Trend in Caesarean Section Rates: Global, Regional and National Estimates: 1990-2014. PLoS One 2016; 11(2): e0148343. https: / / doi.org/10.1371/journal.pone.0148343

2. Brasil. Ministério da Saúde. DATASUS. Sistema de Informações sobre Nascidos Vivos - SINASC [Internet]. Brasília: Ministério da Saúde; 2018 [acessado em 31 out. 2020]. Disponível em: http: / / tabnet.datasus.gov. $\mathrm{br} /$ cgi/tabcgi.exe?sinasc/cnv/nvuf.def

3. Nakamura-Pereira M, Leal MC, Esteves-Pereira AP, Domingues RMSM, Torres JA, Dias MAB, et al. Use of Robson classification to assess cesarean section rate in Brazil: the role of source of payment for childbirth. Reprod Health 2016; 13(Supl. 3): 128. https:/ / doi. org/10.1186/s12978-016-0228-7 
4. Brasil. Ministério da Saúde. Secretaria de Ciência, Tecnologia e Insumos Estratégicos. Comissão Nacional de Incorporação de Tecnologias no SUS. Diretrizes de atenção à gestante: a operação cesariana [Internet]. Brasília: Ministério da Saúde; 2015 [acessado em 21 jan. 2021]. Disponível em: https: / / portaldeboaspraticas.iff. fiocruz.br/biblioteca/diretrizes-nacionais-de-atencaoa-gestante-operacao-cesariana/

5. Mascarello KC, Matijasevich A, Santos IS, Silveira MF. Complicações puerperais precoces e tardias associadas à via de parto em uma coorte no Brasil. Rev Bras Epidemiol 2018; 21: e180010. https://doi. org/10.1590/1980-549720180010

6. Kallianidis AF, Schutte JM, van Roosmalen J, van den Akker T, Maternal Mortality and Severe Morbidity Audit Committee of the Netherlands Society of Obstetrics and Gynecology. Maternal mortality after cesarean section in the Netherlands. Eur J Obstet Gynecol Reprod Biol 2018; 229: 148-52. https: / / doi. org/10.1016/j.ejogrb.2018.08.586

7. Santos IS, Barros AJ, Matijasevich A, Zanini R, Chrestani Cesar MA, Camargo-Figuera FA, et al. Cohort profile update: 2004 Pelotas (Brazil) Birth Cohort Study. Body composition, mental health and genetic assessment at the 6 years follow-up. Int J Epidemiol 2014; 43(5): 1437-1437a-f. https:// doi.org/10.1093/ije/dyu144

8. Barros AJ, Victora CG. Indicador econômico para o Brasil baseado no censo demográfico de 2000. Rev Saúde Pública 2005; 39(4): 523-9. https: / / doi.org/10.1590/ S0034-89102005000400002

9. StataCorp. Stata Statistical Software: Release 14. College Station: StataCorp LP; 2015.

10. Axelsson D, Brynhildsen J, Blomberg M. Postpartum infection in relation to maternal characteristics, obstetric interventions and complications. J Perinat Med 2018; 46(3): 271-8. https: / doi.org/10.1515/jpm-2016-0389

11. Liu X, Landon MB, Cheng W, Chen Y. A comparison of maternal and neonatal outcomes with forceps delivery versus cesarean delivery. J Matern Fetal Neonatal Med 2020; 33(2): 307-13. https:/ / doi.org/10.1080/147670 58.2018.1490720

12. Esteves-Pereira AP, Deneux-Tharaux C, NakamuraPereira M, Saucedo M, Bouvier-Colle MH, Leal MC. Caesarean Delivery and Postpartum Maternal Mortality: A Population-Based Case Control Study in Brazil. PLoS One 2016; 11(4): e0153396. https:/ / doi.org/10.1371/journal.pone.0153396

13. Rortveit G, Hannestad YS. Association between mode of delivery and pelvic floor dysfunction. Tidsskr Nor Laegeforen 2014; 134(19): 1848-52. https:// doi. org/10.4045/tidsskr.13.0860
14. World Health Organization. WHO Statement on Caesarean Section Rates. Genebra: World Health Organization; 2015. (WHO/ RHR/15.02.)

15. Liu S, Liston RM, Joseph KS, Heaman M, Sauve $\mathrm{R}$, Kramer MS. Maternal mortality and severe morbidity associated with low-risk planned cesarean delivery versus planned vaginal delivery at term. CMAJ 2007; 176(4): 455-60. https://doi.org/10.1503/ cmaj.060870

16. Thurn L, Wikman A, Westgren M, Lindqvist PG. Massive blood transfusion in relation to delivery: incidence, trends and risk factors: a population-based cohort study. BJOG 2019; 126(13): 1577-86. https:// doi.org/10.1111/1471-0528.15927

17. Villar J, Carroli G, Zavaleta N, Donner A, Wojdyla D, Faundes A, et al. Maternal and neonatal individual risks and benefits associated with caesarean delivery: multicentre prospective study. BMJ 2007; 335(7628): 1025. https:// doi.org/10.1136/bmj.39363.706956.55

18. Lumbiganon P, Laopaiboon M, Gülmezoglu AM, Souza JP, Taneepanichskul S, Ruyan P, et al. Method of delivery and pregnancy outcomes in Asia: the WHO global survey on maternal and perinatal health 2007-08. Lancet 2010; 375(9713): 490-9. https:/ / doi. org/10.1016/s0140-6736(09)61870-5

19. Burrows LJ, Meyn LA, Weber AM. Maternal morbidity associated with vaginal versus cesarean delivery. Obstet Gynecol 2004; 103(5 Pt 1): 907-12.

20. Bodelon C, Bernabe-Ortiz A, Schiff MA, Reed SD. Factors associated with peripartum hysterectomy. Obstet Gynecol 2009; 114(1): 115-23. https: / doi. org/10.1097\%2FAOG.0b013e3181a81cdd

21. Molina G, Weiser TG, Lipsitz SR, Esquivel MM, UribeLeitz T, Azad T, et al. Relationship Between Cesarean Delivery Rate and Maternal and Neonatal Mortality. JAMA 2015; 314(21): 2263-70. https:// doi.org/10.1001/ jama.2015.15553

22. Souza JP, Gülmezoglu A, Lumbiganon P, Laopaiboon M, Carroli G, Fawole B, et al. Caesarean section without medical indications is associated with an increased risk of adverse short-term maternal outcomes: the 2004-2008 WHO Global Survey on Maternal and Perinatal Health. BMC Med 2010; 8: 71. https:/ / doi. org/10.1186/1741-7015-8-71

23. D’Agostino Jr. RB. Tutorial in Biostatistics - propensity score methods for bias reduction in the comparison of a treatment to a non-randomized control group. Stat Med 1998; 17(19): 2265-81. https: / / doi.org/10.1002/ (sici)1097-0258(19981015)17:19\%3C2265::aid$\operatorname{sim} 918 \% 3 \mathrm{E} 3.0 . \mathrm{co} ; 2-\mathrm{b}$ 
24. Patorno E, Grotta A, Bellocco R, Schneeweiss S. Propensity score methodology for confounding control in health care utilization databases. Epidemiol Biostat Public Health 2013; 10(3): 8940-16. https:// doi.org/10.2427/8940

25. Santos IS, Matijasevich A, Silveira MF, Sclowitz IK, Barros AJ, Victora CG, et al. Associated factors and consequences of late preterm births: results from the 2004 Pelotas birth cohort. Paediatr Perinat Epidemiol 2008; 22(4): 350-9. https:// doi. org/10.1111/j.1365-3016.2008.00934.x

Received on: 11/10/2020

Revised on: 02/01/2021

Accepted on: 02/11/2021
Authors' contributions: Keila Cristina Mascarello: analysis and interpretation of the data, drafting of the manuscript and approval of the final version. Alicia Matijasevich: conception of the study, drafting of the manuscript and approval of the final version. Aluísio J. D. Barros: conception of the study, drafting of the manuscript and approval of the final version. Fernando C. Barros: conception of the study, drafting of the manuscript and approval of the final version. Iná S. Santos: conception of the study, drafting of the manuscript and approval of the final version. Jeremy Alexander Labrecque: analysis and interpretation of the data, drafting of the manuscript and approval of final version. Mariângela Freitas Silveira: conception of the study, drafting of the manuscript and approval of the final version . 